\title{
MULTIAGENT COLLABORATIVE COMPUTATION FOR AIRCRAFT MAINTENANCE SYSTEM
}

\author{
Arwin Datumaya Wahyudi Sumari, Adang Suwandi Ahmad \\ Cognitive Artificial Intelligence Research Group (CAIRG) \\ School of Electrical Engineering and Informatics, Institut Teknologi Bandung \\ Achmad Bakrie Building, $3^{\text {rd }}$ Floor \\ Jl. Ganeca 10, Bandung-40132, INDONESIA \\ Email : \{arwin.sumari, adangsahmad\}@yahoo.com
}

\begin{abstract}
Quick-and-accurate decision is a primary requirement for achieving a mission's successfulness in many organizations whether they are militaries or civilians. The larger and more complex the scope of a mission the longer the time will be needed to perform decision-making. $A$ complex mission such as retaining a sustainable mission of aircrafts deployed in certain remote bases will require a 24-hour of standby on-site or off-site maintenance teams. The most common problem arisen from humans in such situations is the fatigue that can occur anytime to any of them during a contimuing mission and of course, it can affect the continuity of the mission and delay or disappoint the mission achievement. In this paper we address the concept of the utilization of Multiagent Collaborative Computation (MCC) paradigm in supporting the decision-making process in aircrafts maintenance during a sustainable mission in remote bases. The ultimate goal of the MCC-based aircraft maintenance system is comprehensive information regarding the maintenance procedures in order to keep the aircrafts serviceable during the mission implementation. In this paper we also present the technique to obtain the comprehensive information as the basis for decision-making called A3S (Arwin-Adang-AciekSembiring) information-inferencing fusion method.
\end{abstract}

Keywords : A3S, aircraft maintenance, decision-making support system, informationinferencing fusion, multiagent collaborative computation

1. Introduction

Our country is an archipelagic nation with vast areas viewed from its sea area as well as air area as depicted in Fig. 1. This situation, aware or not, brings vulnerabilities such as illegal trespassing, illegal fishing, illegal flight, and etc via open paths as pointed by arrows in Figure 1. In order to prevent the emergence of this vulnerability as well as to protect the sovereign of our nation, Indonesian Air Force deploys air patrol flight in some strategic locations called as remote bases.

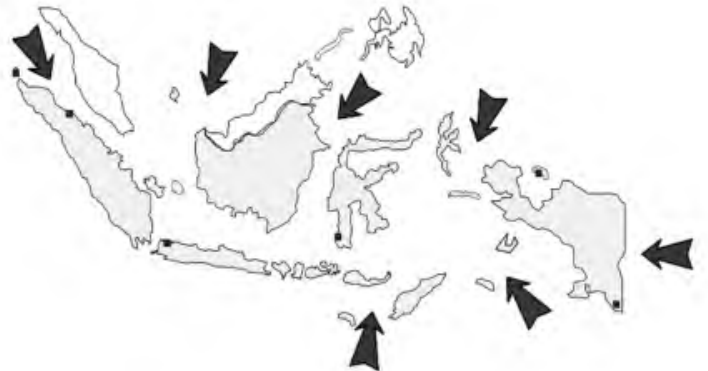

Figure $1 \mathrm{~A}$ simplified scenario of NCW paradigm.

The deployment of aircrafts in remote locations brings some consequences such as logistics and personnel support so as to retain the continuity of the mission. Parts of the logistics are maintenance team as well as spare part supports for not only the aircrafts but also aircrafts' ground equipment and facilities. The primary problem occurred in humans is fatigue that can take place anytime anywhere during the mission. 
In order to cope with these problems, in this paper we address our view of the utilization of Multiagent Collaborative Computation (MCC) to decision-making process in aircrafts maintenance deployed in remote locations. The multiagent approach is aimed to replace humans in some maintenance tasks, while collaborative computing is a mechanism that will be done by multiagent to deliver information as the basis for decision-making in aircraft maintenance.

The structure of the paper is as follows. Section 1 covers the paper's background and followed by Section 2 which covers related matters to multiagent and collaborative computing as well as state-of-the-art related to the idea presented in the paper. In Section 3 we deliver the concept of MCC-based Decision-Making Support System (MCCDMSS) applied to the maintenance system of aircrafts which are deployed in a remote area. We also deliver the technique for obtaining comprehensive information as the basis for the decision to be made in MCCDMSS. The paper converges in Section 4 with the conclusions of the presented paradigm in the paper.

\section{Fundamental Theories}

In this section we deliver the concept of multiagent preceded with the idea of what an agent is. We also present the definition of collaborative computing as well as state-ofthe-art of its application.

2.1 The Concept of Agent[1]

In real life, agent is defined as a thing that causes a significant effect on a situation. In order to give this effect, agent must have capabilities. "Capability" in this circumstance is the ability to manage when the tasks will be carried out, knows where to move, knows how to do the tasks, knows the success level of the tasks being carried out, and the consequences of the tasks being done. All of these capabilities are easy to be accomplished by human agent because he/she has five sense organs (eyes, ears, nose, tongue, and skin) as the sensors and other parts of the body such as arms and legs as the effectors. The main thing that enables the agent in performing its activities is the brain, a place where the information processing is carried out. This is the most grandeur that is not possessed by other living things.

In accomplishing the assigned tasks, the agent always senses his/her surrounding environment to get as much as information that can affect his/her activities. The gathered information is processed in his/her brain, combining it with the existing information to obtain fused information, inferencing on the fused information, information-inferencing fusion, and making the best decision for actions to be done in anticipating the environment dynamics.

In many literatures, agent is stated must have an intelligent characteristic. However, because there is no uniform definition of what agent is, one common consensus is taken that autonomy or we call this as selfgoverning, is the essential characteristic. Self-governing means the agent has capability to instruct itself to accomplish the tasks and do self-evaluation to value the success rate of the assigned tasks accomplishment for future enhancement.

\subsection{Multiagent System[1]}

An agent alone has limitations in achieving the objectives. In some cases single agent is considered enough to do certain simple tasks. When the problems at hand get more complex, single agent probably can still do the tasks but there will be consequences that have to be considered such as speed and time. These two parameters are the influent factors in information processing that covers the time that is taken to deliver the information from information multi-source up to the fused inferencing is ready to be used as the basis for decision making.

Multi-agent system is a system that consists of a number of agents which interact with one another typically by exchanging messages through some computer network infrastructure. Multiagent system is aimed to cope with more complex, realistic, and large scale problems that cannot be handled by single agent and to find one solution of global problems or controlling complex systems.

2.3 What is Collaborative Computation?[3]

Collaboration is taken from the Latin word "collaborare" meaning "to work 
together", while "collaborative" is an adjective form of "collaboration". So, collaboration is defined as to work with another or others on a joint project or in deeper definition is a process in which entities share information, resources and responsibilities to jointly plan, implement, and evaluate a program of activities to achieve a common goal. In collaborative scheme, a group of entities enhance the capabilities of each other that implies in sharing risks, resources, responsibilities, and reward. Collaboration involves mutual engagement of participants to solve a problem together, which implies mutual trust and thus takes time, effort, and dedication.

On the other side, "computation" is defined as a calculation involving numbers or quantities. Along with the fast developing of Information and Communication Technology (ICT), the computational approach can be done even more faster than before because of the advancement of the computation systems. By employing computational approach, we can manipulate a large database to solve problems at hand very fast. The consequence is faster, more complete, and more accurate results than that can be achieved by conventional approach. By combining the two definitions previously explained, we define "collaborative computation" as a calculation on quantities done by a group of agent that work together to achieve common or joint goals.

\subsection{Multiagent Collaborative Computation}

We have noted that a single agent has limited capabilities when is faced with complex problems viewed from the speed and the time taken in performing information-processing. On the other hand, the term "collaborative computation" requires that more than one agent to form a collaborative structure in order to be able to work collaboratively in solving problems.

In MCC scheme, each agent in the collaborative framework performs its own tasks to achieve its own goals. The goals achieved by each agent actually are partial parts of joint goal, which is the combination of partial goals. In simple word, the system is given a problem along with the goal that has to be achieved. The problem is then divided into several sub-problems that have to be solved by the agents. In achieving the sub-goals, the agents perform computation in parallel. The achieved sub-goals are then combined to become a single comprehensive goal that is called as joint goal.

By taking into consideration the mechanism occurred in MCC scheme, we define "multiagent collaborative computation" as a calculation on quantities done by a multiagent system in order to achieve a goal where the goal is the combination of sub-goals achieved by each agent that performs the computation in parallel manner. The concept of MCC is simply depicted in Figure 2. This concept is the enhancement of the one proposed by Sumari et.al.[4]

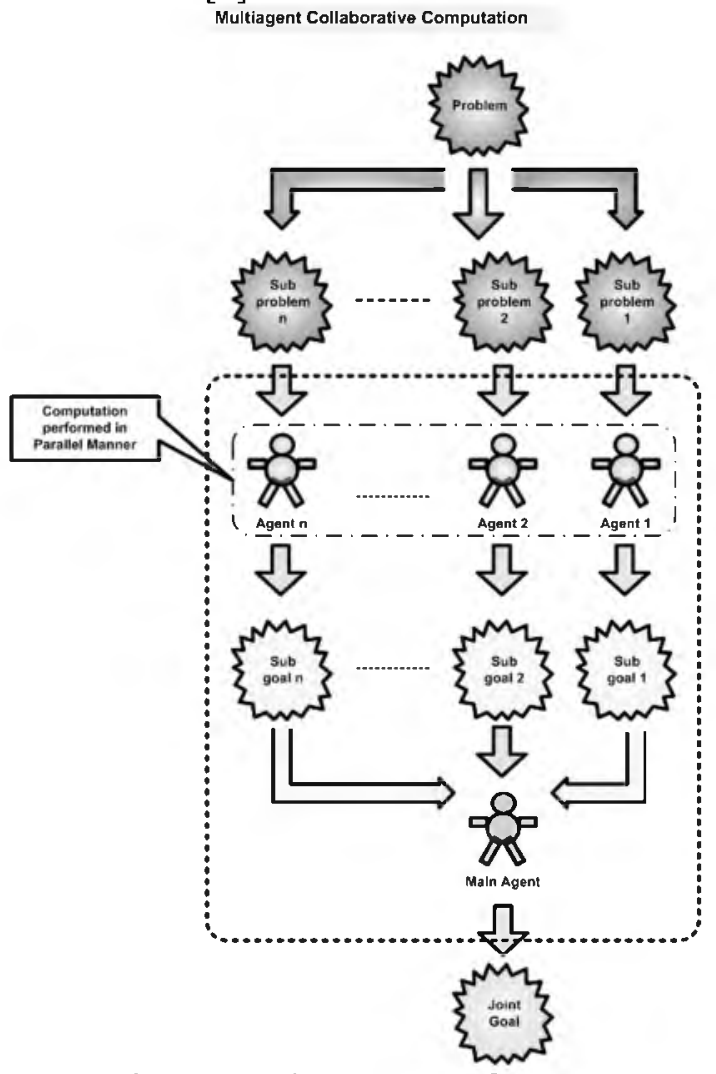

Figure. 2 The concept of MCC.

\section{The Study Case}

In this section we will deliver the utilization of the concept of MCC to DMSS in an aircraft maintenance system. The reason why we deliver the concept of MCCDMSS is the operational readiness of the 
aircrafts is the initial point of the mission successfulness. The sustainable readiness can be achieved if the maintenance can be performed in a minimum time, therefore according to Lung and Morel[5], the maintenance activities should become more and more agile, adaptable, rapid, and with low cost. In order to show how the concept works, we create a simple scenario as follows.

Our nation is an archipelagic country most of its area is covered by waters with a vast area in the air as depicted previously in Figure 1. The most possible means to cover our nation's areas that can reach every single point in every direction in very quick manner is by using the aircrafts. One of the missions is air patrol mission that is carried out in the patrol regions as depicted in Figure 3 by a group of aircrafts. In order that the mission can be accomplished properly, the groups of aircrafts are deployed in some strategic remote bases far from their home bases. Such in this case, the remote base for Region 1 may be Medan Air Force Base (AFB), Region 2 may be Halim Perdanakusuma AFB, Region 3 may be Hasanuddin AFB, and Region 4 may be Biak AFB.

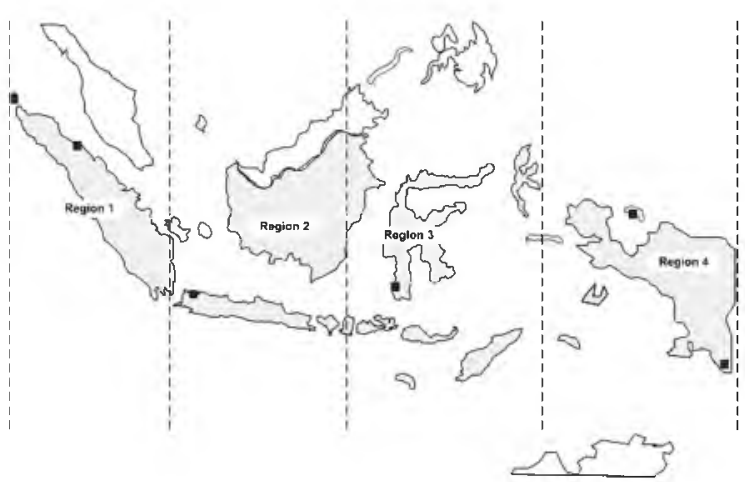

Figure. 3 Our nation's sovereignty and air patrol regions division. This situation is adapted from Sumari et.al.[6]

Air patrol mission is a strategic mission in whom the personnel involved in the mission, not only the pilots but also the technicians must be vigilance in 24-hour time. The common problem usually occurs in this situation is the fatigue that can happen to any of them anytime. In this paper we only concentrate on the maintenance system that consists of people who have responsibility to ascertain that the aircrafts are serviceable during the carrying out of the air patrol mission for a long period in remote bases and system that supports the maintenance procedures.

The aim of the utilization of MCC in this situation is to anticipate the fatigue that can be occurred to any maintenance personnel and to support the decision-making process in aircrafts maintenance system, i.e. the aircrafts operational readiness

\subsection{The Mission Scenario}

In the same manner as previously stated, the mission is air patrol mission that will be carried out from a remote base far from the aircrafts' home base. In order to accomplish the mission successfully, the mission commander is supported by some staffs which some of them are Operation (O), Personnel (P), and Logistics (L) staffs. Each staff creates a plan according to its main objective within the mission's goal scope. In the effort to achieve own main objective, each commander's staff is also supported by the hierarchy below it. Figure 4 depicts a simple mission's organization.

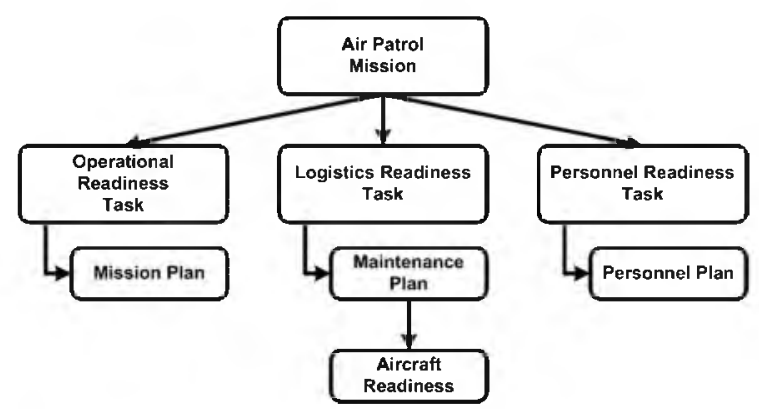

Figure. 4 A simple example of a mission organization.

\subsection{The Strategy for Accomplishing the Mission's Goal}

The successfulness of the mission is relied on the successfulness of the three parties in accomplishing their own objective, that is, operational, logistics, and personnel readiness. The aircrafts operational readiness is depended on the correct and quick maintenance by qualified technicians and supported by on-time spare parts and maintenance tools. 


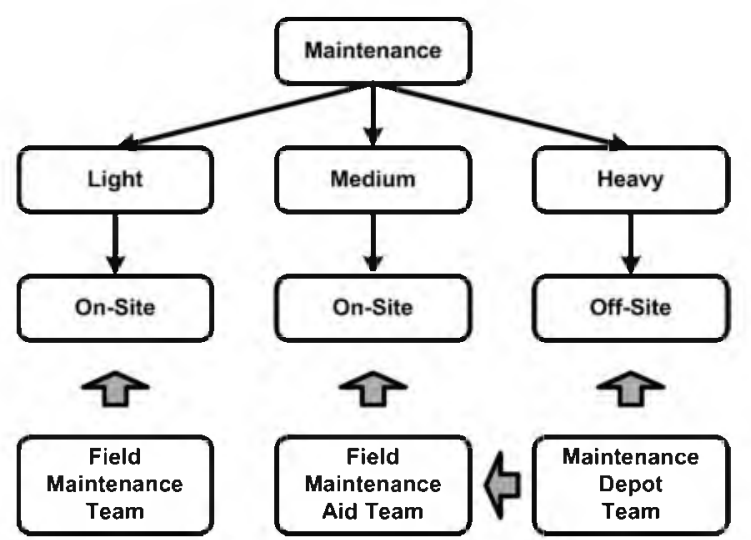

Figure. 5 Levels of aircraft maintenance.

According to the aim of the paper, we only focus on the aircrafts maintenance which one of important aspects in operational readiness. The successfulness of the maintenance aspect itself is influenced by three important factors, namely the level of maintenance, the availability of the maintenance tools, and the availability of the spare part. The maintenance aspect is depicted in Figure 5.

\subsection{The Concept of the Implementation of} MCC-DMSS

Before devising the most likely multiagent architecture to supporting the mission accomplishment, we have to describe the tasks performed by the mission commander as well as the task of his staffs as follows.

Mission Commander (M). M's tasks are execute and monitor the carrying out of the mission, coordinating and instructing OLP staffs regarding the mission dynamics, and report to the headquarter regarding the mission accomplishment.

Operation (O) Staff. O staff's tasks are plan the mission, calculate the number of aircrafts flown as well as the weapon needed to support the mission, monitors and reports the readiness status of the aircrafts as well as their supporting equipment to the commander. $O$ staff also coordinates with $\mathrm{L}$ staff regarding the aircrafts operational readiness and with $P$ staff regarding the air and ground crews readiness.

$\square$ Logistics (L) Staff. L staff's tasks are prepare the aircrafts as well as their supporting equipment and matters, monitors the maintenance status of the aircrafts, monitor the status of the spare parts, coordinate with $\mathrm{O}$ staff regarding the status of the aircrafts, with $\mathrm{P}$ staff regarding the technicians required for aircrafts maintenance. $L$ staff reports to the commander regarding the status of logistics readiness of the mission. L staff also decides the status of aircraft readiness to support the mission.

$\square$ Personnel (P) Staff. P staff's tasks are monitor the status of all personnel who support the mission, arrange on/off-duty personnel, and coordinate with $\mathrm{O}$ and $\mathrm{L}$ staffs regarding the personnel required to support the mission. P staff also decides the status of personnel readiness to support the mission.

1) MCC-DMSS Objectives: MCC-DMSS is aimed to provide comprehensive information regarding the readiness of all parties in supporting the mission to achieve its goal. The information obtained by MCC-DMSS is used to as the basis for the decision made by the commanding officer to execute the mission. The final result of MCC-DMSS is the fusion or combination of decisions made by its lower level hierarchy. The decision flow is depicted in Figure 6.

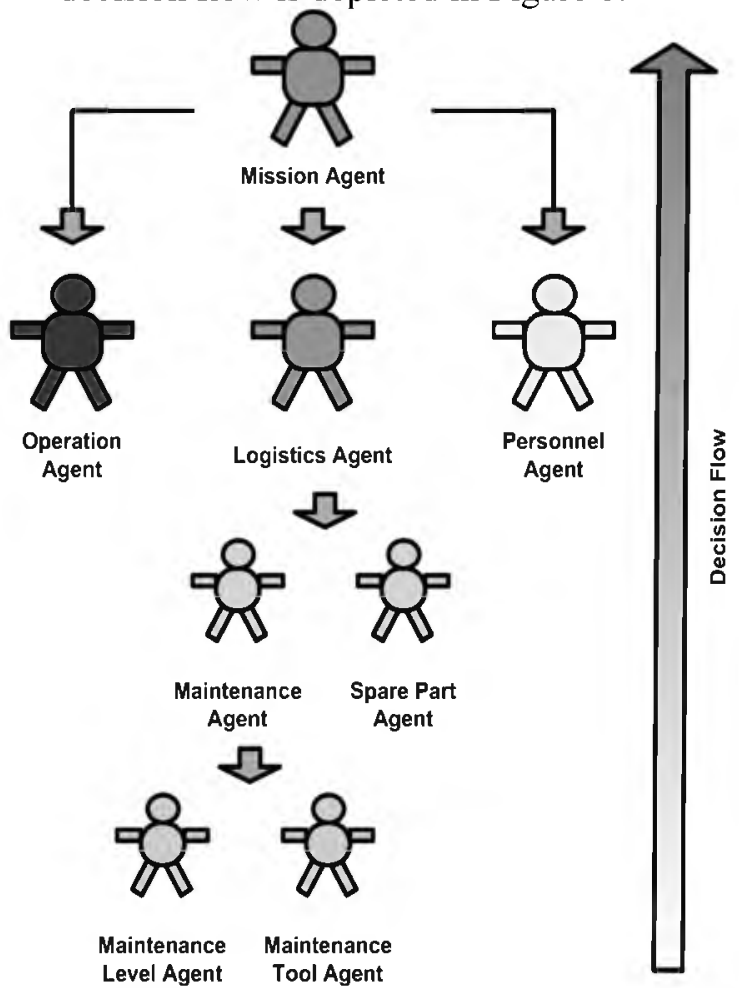


Figure. 6 The architecture of the MCC and the direction of the decision flow

(see the arrow at the right side)

2) MCC Architecture: According to each party tasks and their relation to each other described previously, there will be four agents who consist of one principal agent namely Main $(\mathrm{M})$ agent and three supporting agents namely Operation $(\mathrm{O})$ agent, Personnel (P) agent, and Logistics (L) agent. Because we only focus on the maintenance aspect, $\mathrm{L}$ agent will be supported by two agents namely Maintenance agent $(\mathrm{mA})$ and Spare part agent (sA), while $\mathrm{mA}$ will be supported by maintenance Tool agent (mTA) and maintenance Level agent (mLA). The architecture of the MCC is depicted in Figure 6. The tasks of agents under $\mathrm{L}$ agent coordination are as follows.

$\neg \mathrm{mA}$ monitors any aircraft's unserviceable status delivered from $\mathrm{L}$ agent. If there is a status, $\mathrm{mA}$ evaluates it and determines what type of appropriate maintenance level will be performed to the aircraft. It also sends an instruction to mLA to make necessary coordination regarding the status of the maintenance level to related parties.

$\square$ sA monitors any aircraft's unserviceable status delivered from $\mathrm{L}$ and searches in its database the spare parts needed for servicing the aircraft. It also automatically performs a necessary coordination with central spare part database if its database does not keep the needed spare parts.

$\square$ mLA performs necessary coordination to maintenance depot if the status of maintenance level is Medium and Heavy. The maintenance status in these levels will require advices and in some cases, Field Maintenance Aid Team (FMAT) has to be asked for help to perform the on-site maintenance.

$\square$ mTA prepares the necessary maintenance tools will be needed for the aircraft's maintenance process. It also can perform necessary coordination to maintenance depot regarding the special tools needed for aircraft maintenance.

\subsection{The Computation Mechanism in MCC}

We have designed the MCC architecture that represents the mission organization with the focus on L staff which has an authorization to decide the status of aircraft readiness to support the mission. The essential matter in a multiagent paradigm is the mechanism performed by the agents in solving the given problems. Therefore, in this section we have designed the internal mechanism within agents to perform collaborative computation.

Referring to Section 3.1 and 3.2, we do top-bottom approach, that is, a mission is divided by $M$ agent into several submissions and distributed them to OLP agents. $\mathrm{L}$ agent divides its sub-mission into sub-submissions and distributes them to $\mathrm{mA}$ and sA agents. $\mathrm{mA}$ coordinates $\mathrm{mLA}$ and mTA agents to obtain the best maintenance procedure. Because of these reasons, we design the computing mechanism for $\mathrm{M}$ agent and for OLP agents.

1) Main Agent: The mechanism of computation in $\mathrm{M}$ agent is depicted in Figure 7. In very simple words, the mechanism is as follows. $M$ agent checks for any mission given by the mission commander. After receiving a mission, $\mathrm{M}$ agent analysis it and searches the similar missions in its Knowledge Base (KB), then starts dividing it into several submissions that will be distributed to OLP agents. At the final process, $M$ agent gathers the sub-goals obtained by OLP agents and do sub-goals fusion to obtain a single comprehensive goal. The fusion result is also consulted with the mission analysis's result in order to ascertain the correctness of the obtained goal.

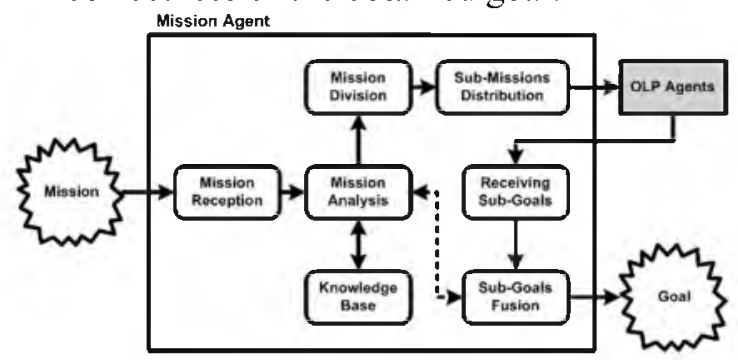

Figure. 7 The architecture of $\mathrm{M}$ agent. 
2) OLP Agents: OLP agents monitor any instruction given by $M$ agent. After receiving an instruction, each agent does the tasks according to their responsbilities. They analyse the submissions, compare them with the existing ones in $\mathrm{KB}$, and perform the submissions to obtain sub-goals. All subgoals are then delivered to $M$ agent to be processed further. The mechanism of the computation in OLP agents is depicted in Figure 8.

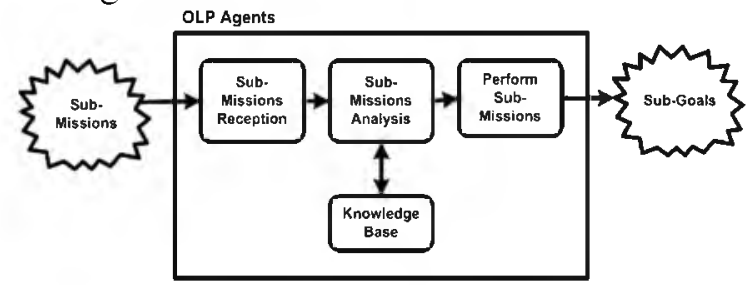

Figure. 8 The architecture of OLP agent.

3) Detailed of L Agent: Specifically, to L agent, it is supported by $\mathrm{mA}$ and sA. $\mathrm{mLA}$ of $\mathrm{mA}$ has a capability to assess the level of maintenance of the aircraft according to the unserviceable information. The assessment result is coordinated with mTA to inform the appropriate tools to make the aircraft serviceable. The detailed architecture of $\mathrm{L}$ agent is depicted in Figure 9.

In general, after $\mathrm{L}$ agent receives a sub-mission from $M$ agent, it analyzes it and performs it by sending the tasks to $\mathrm{mA}$ and sA. $\mathrm{mA}$ analyzes the appropriate level of maintenance that should be done to return the aircrafts to their serviceable condition and sends the result to mLA and mTA to carry out necessary actions. If the level is Medium or Heavy status, the two agents will automatically access the central database and central help desk to ask for help.

mLA also calculates the time needed to do the service after the needed spare parts available with the appropriate tools calculated by mTA. The helps can be in form of maintenance advices or FMAT delivery to the location.

On the other hand, sA immediately checks the on-site spare part database of the needed parts availability. In the outof-stock spare parts situation, it has a capability to access the central database to find the appropriate spare parts and calculates the time needed to bring them to on-site. The concept of accessing the central database and help desk is adapted from the concept of remote maintenance of weaponry system proposed by Sumari[7].

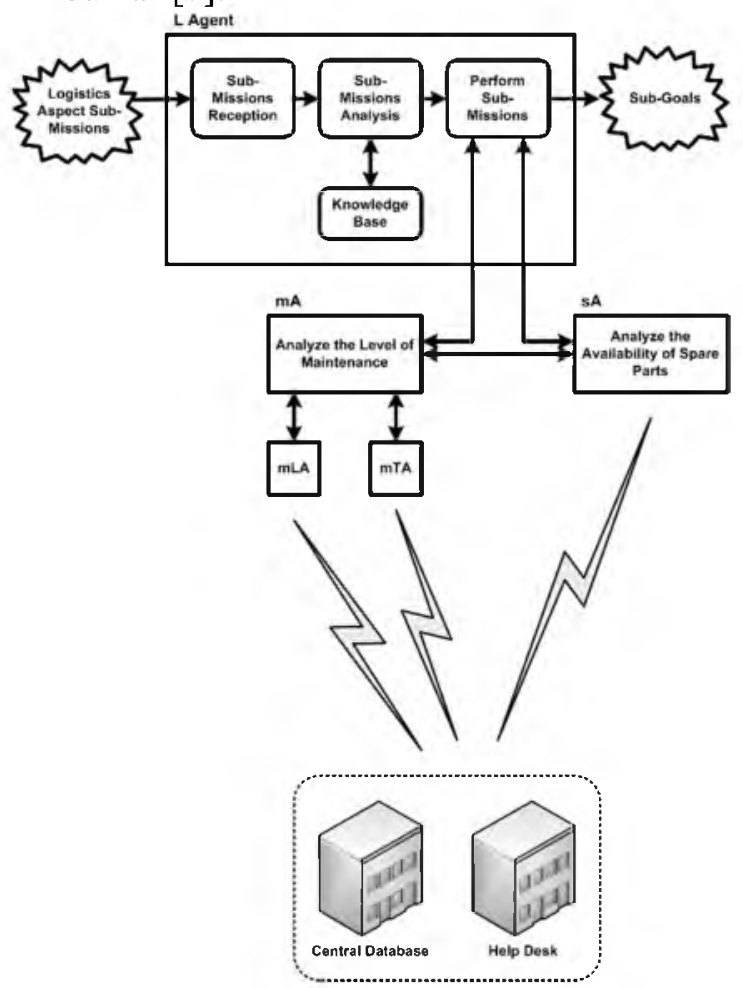

Figure. 9 The detailed architecture of $\mathrm{L}$ agent.

\subsection{Techniques for Obtaining \\ Comprehensive Information}

Of ways in obtaining comprehensive information from multiple information sources or information multi-source is by fusing or combining the collected information by using a technique called information fusion. The concise explanation of the concept and the application of information fusion can be referred to Sumari et.al.[2][9]. We have developed a method of information fusion that is built from the perspective of intelligent characteristic presented by the human brain when performing information fusion. In short, the ultimate goal of this mechanism is new knowledge which already covers all information collected by the information multi-source, which is in this case are the human's sensory organs. 
Based on the investigations on this mechanism, we have proposed a new method called A3S (Arwin-Adang-AciekSembiring) information-inferencing fusion method[8] which is the enhancement of Maximum Score of the Total Sum of Joint Probabilities (MSJP) information fusion method introduced by Sumari in $2008[9][10]$. In order to show the differences between the two methods, (1) presents the MSJP method and (2) presents the enhanced A3S method.

$$
\begin{gathered}
P\left(B_{j} \mid A_{i} \& \ldots \& A_{i} \& \ldots \& A_{n}\right)=\frac{\sum_{i=1}^{n} P\left(B_{j} \mid A_{i}\right)}{n} \\
P\left(B_{j} \mid A_{i}\right)_{\text {extimuted }}=\max _{i=1, \ldots, n}\left[P\left(B_{j} \mid A_{1} \& \ldots \& A_{n}\right)\right] \\
P\left(B_{j} \biguplus A_{i}\right)=\frac{1}{n} \sum_{i=1}^{n} P\left(B_{j} \mid A_{i}\right) \\
P\left(B_{j} \biguplus A_{i}\right)_{\text {essimated }}=\max _{i=1, \ldots, n} P\left(B_{j} \biguplus A_{i}\right)
\end{gathered}
$$

where $i=1, \ldots, n$ is the number of hypothesis and $j=1, \ldots, m$ is the number of indication. The $\boldsymbol{P}\left(\boldsymbol{B}_{j}+\boldsymbol{A}_{\boldsymbol{i}}\right)$ notation means as Joint or Fused Probability Distribution (FPD) of all a posteriori probability of all hypotheses. The "estimated" or just "est" term in the two equations means the selected hypothesis is the most likely or probable hypothesis from all available hypotheses given indications. $\boldsymbol{P}\left(\boldsymbol{B}_{j} \square \boldsymbol{A}_{i}\right)_{\text {estimated }}$ is the largest value of $\boldsymbol{P}\left(\boldsymbol{B}_{j} \boxplus \boldsymbol{A}_{i}\right)$ or we call it as Degree of Certainty (DoC). The concept of DoC and its detail explanation can be referred to Sumari et.al.[1-3][6][9][10].

We have enhanced our method by simplying the notations in A3S method. $\boldsymbol{P}\left(\boldsymbol{B}_{j}+\boldsymbol{A}_{i}\right)$ is replaced with $\boldsymbol{P}\left(\psi_{i}^{j}\right)$, while $\boldsymbol{P}\left(\boldsymbol{B}_{j} \mid \boldsymbol{A}_{i}\right)$ is replaced with $\boldsymbol{P}\left(\boldsymbol{\vartheta}_{i}^{j}\right)$ and the number of sensor will be $\delta$. Therefore (2) will become (3). Figure 10 illustrates the computation mechanism occurs in A3S method. $\boldsymbol{P}\left(\psi_{i}^{j}\right)$ is called as New Knowledge Probability Distribution (NKPD). This is knowedge obtained by the agent as the basis for making decision.

$$
\begin{aligned}
& \boldsymbol{P}\left(\psi_{i}^{j}\right)=\frac{1}{\delta} \sum_{i=1}^{\delta} \boldsymbol{P}\left(\vartheta_{i}^{j}\right) \\
& \boldsymbol{P}\left(\psi_{i}^{j}\right)_{\text {estimated }}=\max _{i=1, \ldots, n} \boldsymbol{P}\left(\vartheta_{i}^{j}\right)
\end{aligned}
$$

\begin{tabular}{|c|c|c|c|c|c|c|}
\hline \multirow{2}{*}{$\begin{array}{c}\text { Information } \\
\text { Source }\end{array}$} & \multicolumn{6}{|c|}{ The Possible Combination of Information from } \\
\cline { 2 - 8 } & 1 & 2 & $\cdots$ & $\vdots$ & $\cdots$ & $\lambda$ \\
\hline 1 & $\vartheta_{1}^{1}$ & $\vartheta_{2}^{1}$ & $\cdots$ & $\vartheta_{j}^{1}$ & $\cdots$ & $\vartheta_{\lambda}^{1}$ \\
\hline 2 & $\vartheta_{1}^{2}$ & 0 & $\cdots$ & $\vartheta_{1}^{2}$ & $\cdots$ & $\vartheta_{i}^{2}$ \\
\hline$\cdots$ & $\cdots$ & $\cdots$ & $\cdots$ & $\cdots$ & $\cdots$ & $\cdots$ \\
\hline$j$ & 0 & 0 & $\cdots$ & $\vartheta_{j}^{l}$ & $\cdots$ & $\vartheta_{2}^{\prime}$ \\
\hline$\cdots$ & $\cdots$ & $\cdots$ & $\cdots$ & $\cdots$ & $\cdots$ & $\cdots$ \\
\hline$\delta$ & 0 & 0 & $\cdots$ & 0 & $\cdots$ & $\vartheta_{i}^{s}$ \\
\hline$\Psi$ & $\psi_{1}^{1}$ & $\psi_{2}^{1}$ & $\cdots$ & $\psi_{i}^{1}$ & $\cdots$ & $\psi_{i}^{1}$ \\
\hline
\end{tabular}

Figure. 10 The illustration of the computation mechanism of A3S method

In some cases we still retain $\boldsymbol{P}\left(\boldsymbol{B}_{j}+\boldsymbol{A}_{i}\right)$ notation to show that A3S method is developed from probability theory. Why? As we can see, the way of human thinks is full of considerations or judgments due to the varieties phenomenon he/she observes in his/her environment. In performing a decision-making, he/she always takes into consideration the knowledge he/she already has and compares it with the indications he/she observes to obtain the finest decision. This is what we call as multi-hypothesis multi-indication problems as illustrated in Figure 10. The detail explanation regarding to this matter can be found in Sumari et.al.[10] and Ahmad and Sumari[11]. The new enhancement of the A3S method's formulation can be looked at in Ahmad and Sumari[12-14].

4. Concluding Remarks and Future

Directions

We have presented the concept of the application of MCC-DMSS to aircraft maintenance system in remote bases. It is obvious that the application of intelligent multiagent system in this situation is aimed to:

$\square$ Obtain comprehensive information as the basis for the decision to be made in aircrafts maintenance process in accurate and quick manner.

$\square$ Replace human technicians in some extent in order to minimize incorrect maintenance procedure because of fatigue problems. 
$\square$ Minimize the time needed for aircraft maintenance by performing the tasks in parallel manner.

$\square$ Speed the process of delivering comprehensive information to the decision maker to be used as the basis for decision-making.

The process of obtaining comprehensive information follows the decision flow in bottom-up manner. This situation represents the accommodation of bottom-level agents to contribute in decision-making process. We also showed that the comprehensive information is obtained by fusing the subgoals to become a single goal. For this purpose, we have developed an informationinferencing fusion method called $\mathrm{A} 3 \mathrm{~S}$ which is developed from probability theory. The selection of this basic theory is based on our observations and investigations on the way of human thinks which is represented by the human brain's mechanism in obtaining new knowledge from the information delivered by human's sensory organs. This mechanism is called as information-inferencing fusion.

One of our recent researches regarding the development of information-inferencing fusion method for intelligent agents is called Observation Multi-time A3S (OMA3S)[15] that has been applied to some cases in military as well as non-military fields, such as military operation and planning[6][9][16], and computational biology[3][17]. OMA3S itself is the essential method for our novel approach in AI called Knowledge-Growing System (KGS) namely, a system that capable of growing its knowledge along with the accretion of information as the time passes[14][18][19]. KGS opened a new perspective in Artificial Intelligence called Cognitive Artificial Intelligence (CAI).

KGS as the main engine of CAI has been applied for some real-life problems. Its applications range from decision making to biomedical engineering such as military decision making, power plant energy management [20], dissolved gas analysis for interpreting transformer condition [21], device encryption method [22] and intelligence analysis and estimation [23]. We have been moving forward by transferring KGS algorithm to hardware as steps to develop a Cognitive Processor [24] We have seen many opportunities to apply this kind of processor for humankind such as for intelligent unmanned vehicle.

REFERENCES

[1] Ahmad, A.S., Sumari, A.D.W. Information Fusion in C4ISR Framework: Concept and Application to Nation Defence (IFiND). Proceedings of the International Seminar on C4I Research 2008, South Korea: Ajou University/ROK Joint Chiefs of Staff, 2008: 67-180.

[2] Sumari, A.D.W. et.al. MultiagentBased Information Fusion System in Network-Centric Warfare Paradigm: January 2009, Vol. 2, No. 1, Jurnal Teknologi Komputer COMPILE, Universitas Kristen Maranatha, p. 3955.

[3] Ahmad, A.S., Sumari, A.D.W., Zubir, H.Y. Collaborative Computation in Bioinformatics for Better Life. Prosiding Seminar Nasional Teknologi Informasi dan Aplikasinya 2009, Malang: SENTIA2009, 2009: Keynote Speech.

[4] Sumari, A.D.W., et.al. Sistem Fusi Informasi Berbasis Agen-Agen Kolaboratif untuk Misi-Misi Strategis. Prosiding Seminar Nasional Teknologi Informasi dan Aplikasinya 2009, Malang: SENTIA2009, 2009: F67F72.

[5] Lung B., Morel G. Towards Intelligent Maintenance Integrated within The Enterprise. $\quad 2^{\text {nd }}$ IFAC-IFIP-IEEE Conference on Management and Control of Productions and Logistics, France, 2000: 414-420, Invited Lecture.

[6] Sumari, A.D.W., et.al. The Utilization of A3S Information-Inferencing Fusion to Nation Defense. Prosiding Seminar Nasional Aplikasi Teknologi Informasi 2009, Yogyakarta: SNATi2009, 2009: D21-D26.

[7] Sumari, A.D.W., S.T., M.T., Mayor Lek. The Concept of Remote Maintenance System for Air Weaponry System: 2008, X Edition, Bulletin of Koharmatau, Indonesian Air Force Materiil Maintenance Command, p. 2528. (in Indonesian) 
[8] Sumari, A.D.W. The modeling of A3S (Arwin-Adang-Aciek-Sembiring) information-inferencing fusion method", Bandung: Institut Teknologi Bandung, 2008; 56pp. Technical Report. (in Indonesian)

[9] Sumari A.D.W., Ahmad A.S. Design and Implementation of Multi AgentBased Information Fusion System for Supporting Decision Making (a Case Study on Military Operation): May 2008, Vol. 2, No. 1, ITB Journal of Information and Communication Technology, Institut Teknologi Bandung, p. 42-63.

[10] Sumari, A.D.W. et.al. Pengembangan Teori Probabilitas untuk Fusi Penginferensian Informasi. Prosiding Seminar Nasional Matematika IV 2008, Surabaya: SemNasMatIV2008, 2008: RSP53-60.

[11] Ahmad, A. S., Sumari, A.D.W. MultiAgent Information Inferencing Fusion in Integrated Information System, ITB Publisher, 2008.

[12] Sumari, A.D.W. et.al. Multi-Agent based Information-Inferencing Fusion for Decision Support System. Proceedings of the $2^{\text {nd }}$ International Conference on Computing and Informatics 2009, Malaysia: ICOCI2009, 2009: pp. 90-95.

[13] Sumari, A.D.W. et.al. A Novel Information-Inferencing Fusion for Intelligent Agents. Proceedings of the $2^{\text {nd }}$ International Conference on Electrical Engineering and Informatics 2009, Malaysia: ICEEI2009, 2009: pp. 93-97.

[14] Ahmad, A.S., Sumari, A.D.W. A Novel Perspective on Artificial Intelligence: Information-Inferencing Fusion for Knowledge Growing. Proceedings of the $2^{\text {nd }}$ International Conference on Electrical Engineering and Informatics 2009), Malaysia: ICEEI2009, 2009: Keynote Speech.

[15] Sumari, A.D.W. The modeling of knowledge-growing system based on observation multi-time A3S (OMA3S) information-inferencing fusion method", Bandung: Institut Teknologi
Bandung, 2009; 62pp. Technical Report. (in Indonesian)

[16] Sumari, A.D.W., Ahmad, A.S. The Application of Multiagent Collaborative Computation Concept to Military Operation Planning and Execution. Proceedings of Conference on Information Technology and Electrical Engineering 2009, No. 3, Yogyakarta: CITEE2009, 2009: pp. 3945.

[17] Sumari, A.D.W. et.al. A Novel Approach for Analyzing a Genetic Regulatory System. Proceedings of National Conference on Design and Application of Technology 2009, Surabaya: DAT2009, 2009: pp. 24-31.

[18] Sumari, A.D.W. et.al. Knowledge Growing System: a New Perspective on Artificial Intelligence. Proceedings of the $5^{\text {th }}$ International Conference Information \& Communication Technology and System 2009, Surabaya: ICTS2009, 4 Agustus, Surabaya, 2009: pp. 217-222.

[19] Sumari, A.D.W., Ahmad, A.S. The Development of Knowledge Growing System as a New Perspective in Artificial Intelligence. Proceedings of Conference on Information Technology and Electrical Engineering 2009, No. 3, Yogyakarta: CITEE2009, 2009: pp. 4651.

[20] Mitayani A, Priandana E. R, Mareta R. Knowledge Growing System application in hybrid power plant energy management in Nemberala village Rote Island. Procedia Technology, Vol. 11. 2013: 641-649.

[21] Bachri K.O, Anggoro B, Sumari A.D.W, Ahmad A.S. Cognitive Artificial Intelligence method for interpreting transformer condition based on maintenance data. Advances in Science, Technology and Engineering Systems Journal (ASTESJ) Vol. 2, No. 1. 2017:11371146.

[22] Putra S.D, Ahmad A.S, Sutikno S. Securing encryption device with Knowledge Growing System. In: Proceeding of the $2^{\text {nd }}$ International Conference on Electrical Engineering 
and Computer Science (ICEECS '16); Taipei; 28-29 October 2016. p. EE4.

[23] Sumari A.D.W, Ahmad A.S. Information fusion as knowledge extraction in an information processing system. In: Proceedings of the Fourth International Conference on Advances in Computing, Electronics and
Com.munication (ACEC '16); Roma; 15-16 Dcsember 2016. p. 22-27.

[24] Sereati C.O, Sumari A.D.W, Adiono T, Ahmad A.S. VHDL design for KGS's information fusion algorithm. In: Proceeding of the $2^{\text {nd }}$ International Conference on Electrical Engineering and Computer Science (ICEECS2016); Taipei; 28-29 October 2016. p. EE3. 